\title{
Testing an Informational Theory of Legislation: Evidence from the U.S. House of Representatives
}

Attila Ambrus

Duke University
László Sándor

Harvard University
Hye Young You

Harvard University

October 9, 2012

ERID Working Paper Number 121

This paper can be downloaded without charge from the Social Science Research Network Electronic Paper Collection:

http://ssrn.com/abstract=1990484

\section{Economic Research Initiatives at Duke WORKING PAPERS SERIES

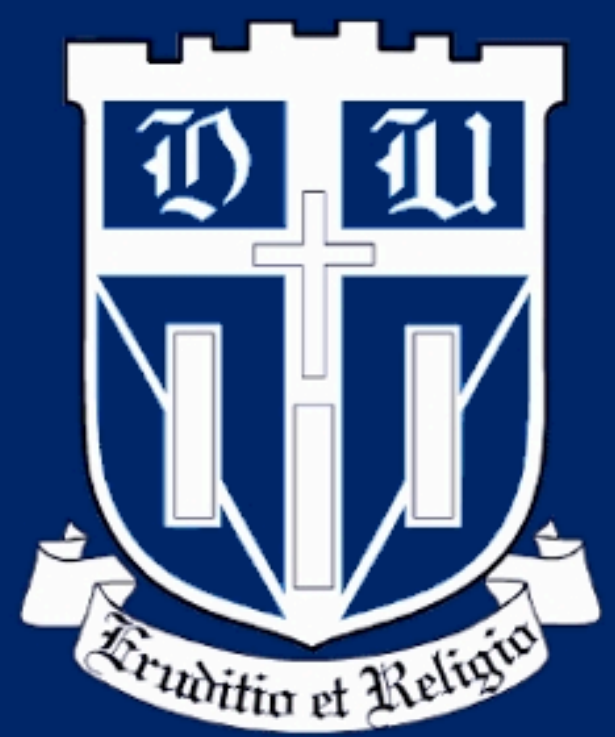




\title{
Testing an informational theory of legislation: Evidence from the U.S. House of Representatives *
}

\author{
Attila Ambrus†, László Sándor; and Hye Young You ${ }^{\ddagger}$ \\ Harvard University
}

October 9, 2012

\begin{abstract}
Using data on roll calls from the U.S. House of Representatives, this paper finds empirical support for informational theories of legislative decisionmaking. Consistent with the theoretical prediction, the bias of the committee a bill gets assigned to is strongly positively associated with the bias of its sponsor, and unbiased sponsors in expectation get assigned to roughly unbiased committees. Moreover, we find a negative relationship between the sponsor's absolute bias and the probability that the legislation is processed by closed rule. Despite these empirical regularities, there is a large variation in the data, suggesting that considerations other than informational efficiency are also important in committee appointments and procedural rule selection. As far as we know, our paper is the first one that provides quantitative empirical support for a theory of communication versus delegation.
\end{abstract}

\footnotetext{
*We thank Yuichiro Kamada, Navin Kartik, Ken Shepsle, Jim Snyder, Joel Sobel, Yuki Takagi for useful suggestions, and especially to Eduardo Azevedo for preliminary data analysis in the early stages of working on the paper.

${ }^{\dagger}$ Department of Economics, Duke University, Durham, NC 27708, email: aa231@duke.edu

${ }^{\ddagger}$ Department of Economics, Harvard University, Cambridge, MA 02138, email: sandor@fas.harvard.edu

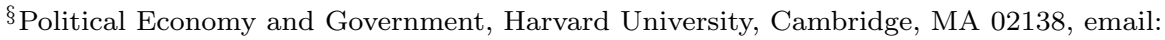
hyou@fas.harvard.edu
} 


\section{Introduction}

Information has long been considered a key factor in explaining why institutions in Congress are organized in a specialized fashion. In their early works, Polsby (1968) and Cooper (1970) argue that information acquisition is the most important goal in legislation, and therefore specialization by committees can be an efficient organizational form to achieve informational advantage. ${ }^{1}$ In a series of influential papers, Gilligan and Krehbiel $(1987,1989)$ offered formal models of legislative decision-making, investigating strategic information transmission within the hierarchical structure of the legislature. ${ }^{2}$ A related theoretical literature, starting with Austen-Smith and Wright (1992) analyzes the role of interest groups in providing information to the legislature through lobbying. ${ }^{3}$ More generally, a large and growing literature in economics examines strategic communication with costless messages (starting with Crawford and Sobel (1982); standardly referred to as cheap talk), delegating decision-making to an informed agent (starting with Holmstrom (1977)), and the trade-offs between delegating decision-power to a biased expert versus retaining the rights to make the decision and communicating with the expert (see for example Aghion and Tirole (1997) and Dessein (2002)). However, as pointed out in a recent paper by Bertrand et al. (2011), the literature has not provided substantial evidence supporting the relevance of these theoretical models, either in the legislative or other contexts. ${ }^{4}$

The findings of the information theory literature on procedural rule selection and committee selection are presented in a unified framework in a recent paper by Ambrus et al. (2011b), from now on referred to as AAKT. The central feature of the model is that an outside interest group, that is biased from the point of view of the legislative body (associated with the preferences of the median legislator), possesses private information relevant for the legislature. The floor, knowing the bias of the interest group, can select a committee to communicate with the interest group, and can also choose whether to delegate agenda-setting power to the committee (in the form of granting closed rule) or not (by selecting open rule, in which case the committee's proposal is only a cheap talk message to the floor). The main findings of the paper are that: (i) if the bias of the lobbyist is small in absolute terms, then it is optimal for the floor to choose closed rule and a committee with perfectly aligned interests with the lobbyist; (ii) if the absolute bias of the lobbyist is from an intermediate range, closed rule remains optimal, but with a committee with preferences strictly between the lobbyist

\footnotetext{
${ }^{1}$ See also Weingast and Moran (1983) and Calvert et al. (1989) on the legislature delegating power to bureaucrats and other agents for informational reasons.

${ }^{2}$ See also Krishna and Morgan (2001) and Krehbiel (2001).

${ }^{3}$ An incomplete list of the literature includes Austen-Smith $(1993,1995)$, Austen-Smith and Wright (1994), Ball (1995), Lohmann (1995), and Bennedsen and Feldmann (2002).

${ }^{4}$ There are laboratory experiments investigating cheap talk, both in the Crawford and Sobel framework (see Cai and Wang (2006) and Wang et al. (2010)), as well as outside that framework (see for example Gneezy (2005) and Kartik and Hurkens (2009)). Outside the lab, Alonso et al. (2008) provide case study evidence supporting their results from a model of centralized versus decentralized coordination in an organization. Malenko (2011) present survey evidence for the type of optimal delegation scheme characterized in the paper. For empirical works in the legislative context, see the next section.
} 
and the floor; (iii) if the absolute bias of the lobbyist is large (but not extremely large to the extent of excluding any possibility of information transmission) then it becomes optimal to choose open rule and a committee adversely biased to the lobbyist. ${ }^{5}$

In this paper we test various predictions of the above model, using information on roll call votes in the U.S. House of Representatives, covering the period from the 107th to the 111th Congresses (January 2001 to January 2011), obtained from the website of the Library of Congress. We do not observe the lobbyist groups associated with different bills, instead we identify the sponsor of the bill as the person in the legislative process originally possessing the relevant private information for the legislature, and test the predictions of the AAKT model with the sponsor taking the place of the interest group. We conduct the analysis under the assumption that the sponsor has the same preferences as the interest group, and therefore the unobserved interaction between the interest group and the sponsor can be regarded as truthful. This is in accordance with a lot of anecdotal evidence that sponsors of bills and organized interest groups frequently work in tandem to advance policy goals that they share. ${ }^{6}$ This approach in particular assumes that the floor cannot influence who becomes the sponsor of a given bill, and the latter is exogenously given as the member of legislature associated with the relevant interest group. An alternative approach would be to assume that the floor, besides choosing the committee and the procedural rule, can also select the identity of the sponsor, and analyze the resulting four-player game in which the interest group transmits information to the sponsor, who in turns transmits information to the committee, who then sends a proposal to the floor. However, as shown in Ambrus and Ivanov (2012), such a model would give the prediction that only closed rule is used in equilibrium. This clearly contradicts the empirical fact that open rule is prevalent in congressional decision-making.

In our basic specification we use the DW-NOMINATE scores of Poole and Rosenthal (for the construction of these scores see Poole and Rosenthal (1985b, 1991a)) to measure the political preferences of different actors. We identify a committee's preferences with the committee chair's preferences, and the floor's preferences with the majority leader's preferences, based on qualitative evidence on the power and influence of these officials (see Section 3 for a detailed discussion). ${ }^{7}$

We focus on testing the main qualitative predictions of the model described above. The predictions are: (i) the probability of closed rule should be a decreasing function of the absolute bias of the sponsor; (ii) small sponsor biases should be associated with small committee biases; (iii) committee bias should be positively

\footnotetext{
${ }^{5}$ AAKT builds on results from Gilligan and Krehbiel (1987), Krishna and Morgan (2001), Dessein (2002), Li (2007), Ivanov (2010) and Ambrus et al. (2011a)). Some of these models, albeit either focus only on selecting a procedural rule, or only on selecting a mediator, give predictions analogous to the ones described for AAKT.

${ }_{7}^{6}$ See Hall and Deardorff (2006).

${ }^{7}$ In the supplementary appendix we also present results from a specification in which the floor is associated with the Speaker's preferences. The latter is a more noisy indicator of the majority party leadership's preferences because the Speaker almost never votes after assuming office, therefore her preferences can only be based on roll call votes beforehand.
} 
associated with sponsor bias, for the region of moderate sponsor biases.

We find distinct support for these predictions in the data.

Although for most of the range of sponsor biases both open and closed rule occur, we find a distinct negative relationship between the magnitude of sponsor bias and the prevalence of closed rule, for the entire range of sponsor biases. Moreover, our nonparametric regression estimation reveals that for sponsor biases close to zero the probability of closed rule is close to 1 , while for very large sponsor biases it is close to 0 .

To investigate the effect of sponsor bias on the choice of committee, we cannot simply regress committee bias on sponsor bias using all bills. This is because the great majority of bills in modern Congress get associated with standing committees, whose membership typically stays roughly constant for the duration of a congressional cycle. Hence, as opposed to the stylized model in AAKT, the bias of the committee cannot be tailored to the bias of a particular sponsor. ${ }^{8}$ For this reason we focus on bills that get referred to multiple committees, indicating that they are in the overlap of jurisdiction of those committees, but one of them gets selected to be the primary committee and receive the right to propose the bill. $^{9}$ For these bills the floor at least has a limited choice (a bit more than 3 on average), approximating the modeling assumptions in AAKT. First, we find that for not too large biases, in accordance with the theoretical predictions, the ultimately chosen committee is very likely to be the one closest to the sponsor, among the potential committees. Second, when using this subsample of bills, we find a significant positive relationship between the bias of the committee and the bias of the sponsor. We also find that the constant term in the linear regression is insignificant, consistent with the prediction that roughly unbiased sponsors get assigned to roughly unbiased committees.

We complement the above analysis by regressing the bias of a committee on the average bias of sponsors that the committee ends up to be associated with as the primary committee. For this investigation we use all bills. The idea is testing whether the typical sponsor the committee is expected to interact with can explain, through the AAKT model, the committee's bias. In this specification we find that the regression coefficient of the average committee bias is close to one, and the intercept is insignificant, which is consistent with the theory that committees are selected to approximate the preferences of typical interest groups they are expected to interact with (provided that the latter are not too biased).

While we find strong empirical regularities that follow from information theoretic models of legislative decision-making, the amount of variation in the data is large. The relationship between sponsor bias and committee bias only holds in expectation, with a relatively large variance. Similarly, for most of the

\footnotetext{
${ }^{8}$ In contrast, in the early days of Congress, bills got typically referred to ad hoc committees. Therefore our model would be a better description of the committee process for this time period. We could not find sufficient data for conducting an empirical analysis of legislative decison-making for this time period, but we hope to do this in future research.

${ }^{9}$ The House first authorized the Speaker to refer measures to more than one committee in the Committee Reform Amendments of 1974. These multiple referrals were used quite frequently in subsequent years (see Koempel and Schneider (2010)).
} 
range of sponsor biases, both open and closed rules are assigned with significant probability.

There are several obvious reasons why the data is not perfectly consistent with the theoretical predictions. First, as we discussed above, the theoretical model is only a rough approximation of the legislative process. Second, informational efficiency is presumably only one of several considerations in committee selection. Other theories of committee formation include the distributive benefits theory, the majority-party cartel theory, and the bicameral rivalry theory (see Groseclose and King (2001) for a discussion on committee theories). It is most likely that some or all of these other considerations also enter into the choice of selecting committee chairs, introducing noise into the relationships predicted by our purely informational theory based model. Third, our measurement of political preferences of different legislators is clearly imperfect, e.g. the bias of a legislator in a particular issue might be different from her computed average bias over many issues. Given the above issues, we find it remarkable that the main qualitative predictions of our informational theory model are clearly verified by the data.

The rest of the paper is structured as follows. Section 2 summarizes the related literature. Section 3 describes the institutional background, with special attention to congressional procedures and the role of committees. Section 4 briefly summarizes the model in Ambrus et al. (2011b) and its main predictions. Section 5 details how the data for the empirical analysis was constructed. Section 6 reports the results of the empirical analysis. Finally, Section 7 concludes. For results from alternative specifications, see the Supplementary Appendix.

\section{Related literature}

The empirical literature on legislative procedures, in particular from the point of view of information transmission, is fairly scarce.

Groseclose and King (2001) consider a list of qualitative stylized facts regarding legislative decision-making, and provide a detailed discussion of which of these facts are consistent with each of four theories of committees (informational efficiency, distributive benefits, majority-party cartel, and bicameral rivalry). Their main conclusion is that none of the proposed theories are consistent with all stylized facts, and suggest that the committee system in the legislature is shaped by multiple different considerations.

Poole and Rosenthal (1997) in Chapter 9 of their book find that most congressional committees in most congresses are not preference outliers, and interpret this as evidence supporting informational theories of committees starting from Gilligan and Krehbiel (1987).

There is a large empirical literature on the role of lobbying in legislature, but only a few of these papers address issues related to information transmission.

Kollman (1997) provides empirical evidence that lobbyist groups in a particular area tend to be like-biased to the committees associated with the same area, which is consistent with our findings. However, the interpretation offered is not information theoretical, instead arguing that members of the legislature 
specializing in a given area are naturally inclined towards the same type of bias as interest groups in that area.

Austen-Smith and Wright (1994) and Hojnacki and Kimball (1998) examine that to what extent lobby groups tend to approach legislators with similar versus different predispositions in an issue.

Langbein (1986) and Wright (1990) provide evidence that money can buy access to legislators, but does not directly influence legislators, suggesting that it is information from the interest group that can shift a legislator's position. Similarly, Ansolabehere et al. (2003) also find that vote buying plays little role in U.S. politics.

Finally, two recent papers, Bertrand et al. (2011) and Banes i Vidal et al. (2011) examine the role of professional lobbyists who serve as intermediators between interest groups and congressmen. ${ }^{10}$

\section{Institutional background}

In this section we describe the timeline of legislative procedures, provide a brief overview of the committee system and legislative rules, and discuss the role of the Speaker, majority leader, committee chairs and bill sponsors in the process.

\subsection{Overview of the legislative process in the House}

Below we provide a description of the legislative process within the House, abstracting away from interaction between the chambers.

Legislation in Congress may be drafted by a member and his or her staff, a committee, lobbyists, executive branch officials, or any combination of insiders and outsiders - but it must be introduced by a member and while Congress is in session. After a draft legislation is introduced in the House, the Speaker refers it to the appropriate committee or committees. In practice, the House parliamentarians inspect the content of proposed legislation, and recommend referral to the committee with the appropriate jurisdiction. ${ }^{11}$

Committees have many options concerning how to process the legislation referred to them. They may approve the legislation and report it back to the House, with or without amendments; reject the measure outright; simply not consider it; or set it aside and write a new bill on the same subject. In practice, most proposed legislation does not survive committee consideration. Committees may send a bill to a subcommittee for initial action or hold it for the full committee to consider. Committee chairs have substantial discretion in deciding whether to refer measures to subcommittees or hold them for full committee consideration.

If a committee intends to act on a bill, it conducts a "markup" on the legislation - a meeting at which the committee or subcommittee reviews the measure line-by-line or section-by-section and considers amendments. Once the

\footnotetext{
${ }^{10}$ See also Salisbury et al. (1989).

${ }^{11}$ Descriptions on legislative process mainly come from Sinclair (2007), Oleszek (2010), Smith (2011).
} 
markup is complete, the measure is reported to the floor if a majority of the committee votes to do so. Committees are free to report legislation with or without amendments or even without a recommendation that the legislation passes. But most important legislation is amended or written as a "clean" committee bill and then recommended to pass.

Legislations that are reported to the floor get scheduled for floor debate by the Speaker. The Speaker also sets the floor agenda. Minor and major legislation are treated differently. In recent years, minor bills have been called up most frequently by unanimous consent requests or by motions to suspend the rules. When legislation is called up by unanimous consent, there is typically no discussion. Under the motion to suspend the rules and pass a bill, debate is limited to no more than 40 minutes, no amendments are allowed, and a two-third majority is required for approval. ${ }^{12}$

Major or controversial legislation is more involved. Many members want to speak and offer amendments, creating a need for procedures that maintain order and expedite action. It is difficult for sponsors of these bills to obtain unanimous or two-thirds majority support, so they turn to the Rules Committee to request a resolution known as a "rule" ${ }^{13}$ Rules are highly flexible tools for tailoring floor action to individual bills. If the Rules Committee grants the bill a procedural rule and a majority of the House supports it, the way is paved for floor debate on the bill. Membership on the House Rules Committee is powerful and prestigious, and it is widely accepted that reforms implemented by House Democrats in the early 1970s firmly established the committee as an arm of the House leadership. ${ }^{14}$

Once a special rule for a measure is adopted, the House resolves to convene "the Committee of the Whole House on the State of the Union" to conduct general debate and consider amendments. A chair appointed by the Speaker presides over the Committee of the Whole. The Committee of the Whole first conducts general debate on the bill and then moves to debate and votes on amendments. Legislation is considered section by section. Voting on amendments can take one of three forms: voice vote, standing division vote, or recorded vote. ${ }^{15}$

Once debate and amending actions are complete, the measure, along with any approved amendments, is reported back to the House. The amendments approved in the Committee of the Whole may then be subject to separate votes; if no one demands separate votes, however, the amendments are voted on as a group.

\subsection{The committee system}

Standing committees are permanent panels identified as such in chamber rules. They consider bills and issues within their legislative jurisdictions, and recommend

\footnotetext{
${ }^{12}$ Sinclare (2007).

${ }^{13}$ Five Committees (Appropriations, Budgets, House Oversight, Rules, and Standards of Official Conduct) have direct access to the floor for certain kinds of legislation.

${ }^{14}$ See Oppenheimer (1977).

${ }^{15}$ Oleszek (2010).
} 
measures for consideration. They also have oversight responsibility to monitor agencies, programs, and activities within their jurisdiction. ${ }^{16}$

The standing Committees in the House are Agriculture, Appropriations, Armed Services, Budget, Education and Labor, Energy and Commerce, Financial Services, Foreign Affairs, Homeland Security, House Administration, Intelligence, Judiciary, Natural Resources, Oversight and Government Reform, Rules, Science and Technology, Small Business, Standards of Official Conduct, Transportation and Infrastructure, Veterans' Affairs, and Ways and Means. The number of standing committees remained stable in the post-war period, although the total number of committee seats grew steadily.

Besides standing committees, select or special committees can be established by a separate resolution of the chamber, sometimes to conduct investigations and studies, and, on other occasions, also to consider measures. There are also joint committees, that are permanent panels that include members from both chambers of legislation, which generally conduct studies or perform housekeeping tasks rather than consider measures. ${ }^{17}$

The party ratios in most committees are close to chamber-wide party ratios. The exception is the Rules Committee, where the majority party has always maintained an oversized representation. Committee assignments are the responsibilities of the party leaders.

\subsection{Legislative rules}

Starting in 1979, the House majority leadership and the Rules Committee began to employ special rules more frequently to restrict floor amendments. Special rules are resolutions from the Rules Committee that, by supplementing or supplanting rules of the House, may structure the amending process in the Committee of the Whole. The change in the content of special rules in the 1980s was dramatic. According to Bach and Smith (1988), between the 94th (1975-76) and 97th (1981-82) Congresses, the percentage of special rules that restricted amendments in some way increased from 15.7 to 28.8 percent. In the 99th Congress (1985-86) 44.6 percent of all special rules limited amendments. These trends continued through the 1990s and 2000s. ${ }^{18}$ In our data set from the 2000s the majority of the bills that reached the vote on passage status were considered via restrictive rules. For the list of special rules used in the Congresses during the time period of our investigation, see Section 5.

\subsection{Key actors in the legislative procedure}

The Speaker

Among the Speaker, the majority leader and the members of the Rules Committee, the Speaker's preference is perceived as the most important factor to

\footnotetext{
${ }^{16}$ Deering and Smith (1997).

${ }^{17}$ Deering and Smith (1997).

${ }^{18}$ See Bach and Smith (1988).
} 
shape legislative outcomes. ${ }^{19}$ The Speaker can schedule her pick of the bills that have been reported from committees. "The power of the Speaker of the House is the power of scheduling," observed by Thomas P. "Tip" O'Neill Jr. (D-MA), who served as Speaker for more consecutive years $\left(1977\right.$ - 1987). ${ }^{20}$

Through use of the Rules Committee and other privileged committees that are considered to be controlled by the Speaker, the Speaker can give priority to a bill she wanted considered or to block a bill she opposes. She could use unanimous consent and suspension of the rules to give access to the floor to bills that she favors and could deny the use of these procedures to bills she opposes. ${ }^{21}$

The volume of legislation before the House makes it exceedingly cumbersome to follow the involved order of business set forth in the rules. For this reason the Speaker usually receives additional power by scheduling.

Finally, the Speaker's position as head of her party provides her with an important source of leverage. Most important issues are regarded as matters on which the party as a whole should stand together. In such a context the Speaker derives considerable power from this position as party chief. If she could not win the support of all elements in the party, she has at her disposal a powerful mechanism for enforcing adherence to her wishes - the caucus. Through a binding vote in the caucus, she could oblige the opposition to support her policy positions out of party loyalty. In short, the Speaker can rule the House through the force of party discipline. ${ }^{22}$

Majority Party Leader

The House of Representatives, with its large membership, has chosen majority and minority leaders to expedite legislative business and to keep their parties united. The role of the majority party leader, also known as the floor leader, is important because she is in charge of scheduling legislation for floor consideration, planning the daily, weekly, and annual legislative agendas, among other functions. ${ }^{23}$ In some cases, majority leaders have been more influential than the Speaker. ${ }^{24}$ The majority leader is in a very close tie with the Speaker and the rules committee to control the legislative procedures in the floor. The majority leader is also responsible for guarding the floor — that is, making sure that business flows smoothly and that opponents do not disrupt the legislative process. Also, the majority leader serves as the Speaker-designated majority-party representative on both the Budget Committee and the Intelligence Committee of the House. ${ }^{25}$

As opposed to the Speaker, who usually does not participate in debates and does not vote on the floor, the majority leader remains an active voting member of the House. For this reason, in our main specification we measure the floor's preferences based on the voting behavior of the majority leader in roll calls.

\footnotetext{
${ }^{19}$ See Cooper and Brady (2009).

${ }^{20}$ Congressional Record, November 15, 1983, H9856.

${ }^{21}$ See Cooper and Brady (2009).

${ }^{22}$ See Cox and McCubbins (1993, 2005).

${ }^{23}$ Office of the Clerk, U.S. House of Representatives.

${ }^{24} \mathrm{~A}$ notable case from our sample period is that Republican majority leader Tom DeLay was considered more prominent than Speaker Dennis Hastert.

${ }^{25}$ See Sinclair (1995).
} 


\section{Committee chairs}

There has been a great deal of discussions on the forms of committee power in Congress. The two principal forms of committee power are negative and positive. Negative committee power is the ability to defend the status quo in the face of those who favor change. In the context of the committee-floor relationship, negative power rests on a committee's ability to restrict the choices available to the floor, and delay proposals reaching the floor. The positive committee power primarily stems from having extra resources and staff that can be used for gathering policy information.

It is well known that the decision whether a committee deals with a bill is largely determined by the chair. The chair exercises considerable control over the committee's agenda, schedules meetings and hearings, normally names conferees, controls the committee budgets, supervises a sizable staff, and often serves as a spokesperson for the committee and party on issues that fall within the committee's jurisdiction. Consequently, the support of the full committee chair is crucial to bill sponsors. ${ }^{26}$

A chair who oppose a bill can refuse or delay to schedule hearings on the bill . On the other hand, a chair who favors a bill can give it top priorities by putting committee resources or facilitating hearings and markups. Chairs are the chief agenda-setter of committees. ${ }^{27}$

Bill sponsors

A Representative who introduces a bill or other measure in the House is called its sponsor. Under House Rule XII, clause 7, several Members together may submit a bill, but the first-named Member is considered the chief or primary sponsor; the others are considered cosponsors. A bill can have only one primary sponsor. The original signature of the primary sponsor must appear on the measure when it is introduced. Cosponsors do not have to affix their signatures to the bill.

Sponsorship formally only identifies the Representative who introduced it, and it does not necessarily indicate support for the measure. In practice, however, members sponsor only bills that they support. It should not be assumed that a bill's sponsor actually drafted it. The bill may have been drafted by a staff member, by an interest group, or by others. However, the primary sponsor is expected to oversee the writing of legislation in general. On occasion, a representative may introduce a bill as a courtesy, such as legislation proposed by the President or senior Administration officials. In such a case, the sponsor may designate the bill as introduced "by request." 28

\footnotetext{
${ }^{26}$ See Deering and Smith (1997).

${ }^{27}$ See Oleszek (2011)

${ }^{28}$ See Sachs (2003), Sullivan (2007).
} 


\section{An information theoretical model of legisla- tion}

Here we briefly summarize the model in AAKT, changing the terminology from lobbyist to sponsor.

We consider a multi-stage game of legislative decision-making with three players: a sponsor, a committee, and the floor. The outcome of the game is a policy action $x \in \mathbb{R}$. The players' preferences over policy actions depend on an ex ante unknown state of the world $\theta$, distributed uniformly on the $[0,1]$ interval.

The payoffs of the floor, the committee, and the sponsor are given by $-(x-\theta)^{2}$, $-\left(x-\theta-b_{C}\right)^{2}$, and $-\left(x-\theta-b_{S}\right)^{2}$, where $b_{C}$ and $b_{S}$ are referred to as the biases of the committee and the sponsor.

The game starts with an ex ante stage (stage 0), in which the floor selects $b_{C}$ and the procedural rule, which can be either open or closed.

In stage 1 , the sponsor observes the realization of $\theta$, and sends a cheap talk message $m \in \mathbb{R}$ to the committee, corresponding to a draft proposal and possibly additional private communication to the committee.

In stage 2 the committee sends a proposal $p \in \mathbb{R}$ to the floor.

Finally, in stage 3 the floor chooses a policy action $x \in \mathbb{R}$. The set of possible choices of the floor in stage 3 depends on the procedural rule chosen in stage 0 . In case of open rule, the floor in stage 3 can select any policy action in $\mathbb{R}$. However, in case of closed rule the floor can only choose between $p$, the policy action corresponding to the proposal, and $s \in \mathbb{R}$, an exogenously given status quo policy commonly known from the beginning of the game. For simplicity it is assumed that the status quo is so undesirable that on the equilibrium path $p$ is always preferred to it by the floor.

The main result in AAKT states that the optimal choices of the floor, for sponsor biases that are not too large to preclude any information transmission, are given by:

- For $b_{S} \leq \underline{b}=1 / 6$, using closed rule and a committee with interests fully aligned with the sponsor: $b_{C}^{*}=b_{S}$.

- For $\underline{b}<b_{S}<\bar{b}=\frac{2+\sqrt{3 / 2}}{10}$, using closed rule and a committee with interests strictly between the sponsor and the floor: $b_{C}^{*} \in\left(0, b_{S}\right)$.

- For $\bar{b}<b_{S}<1 / 2$, using open rule and a committee with interests opposite to the sponsor's: $b_{C}^{*}=-\left(1-2 b_{S}\right) / 3<0$.

For a detailed intuition for these results, see Section 3 in Ambrus et al. (2011b). In short, the floor faces a trade-off between information efficiency, that can be improved by granting closed rule and appointing a committee with aligned interests with the sponsor, and bias, which can be decreased by choosing open rule or appointing a less biased committee than the sponsor. For small enough sponsor value biases informational considerations dominate, leading to closed rule and a committee fully aligned with the sponsor. For large biases open rule 
becomes optimal, and a committee that is biased in the opposite direction as the sponsor, because for such configuration of preferences there exist mixed equilibria of the game in which more information is transmitted than if the floor communicated with the sponsor directly.

AAKT also consider a version of the above model in which in stage 0 the floor can only choose the procedural rule, as the bias of the committee is exogenously given. This is motivated by the fact that in modern congress bills are usually referred to standing committees, the compositions of which typically do not change during a congress. The results in this version of the model are similar to the results regarding the procedural rule in the basic model: closed rule is optimal if the bias of the sponsor is not too large, and the committee's bias is in the same direction and not too large in absolute value relative to the sponsor's.

\section{Data description}

The data set used in this paper covers various information on roll call votes in the U.S House of Representatives. The period the data covers ranges from the 107th Congress, which started in January, 2001 to the 111th Congress that ended in January, 2011. We restricted attention to these relatively recent congresses because there are distinct trends in legislative practices over time, such as a steady increase in the probability of closed rules, that make legislations from congresses far away in time difficult to compare.

The webpage the Library of Congress dedicated to legislative information, THOMAS, provides an excellent online documentation for each roll call vote: It provides the roll call number, the date, the issue number, question, result, sponsor of the bill, the committee that the bill was proposed, and a short description on each bill. ${ }^{29}$ Each congress consists of two sessions and THOMAS has a separate section for each session. The number of roll call votes passed to the floor for voting varies depending on the Congress. For the 107th, 108th, 109th Congresses, the Republican party was in majority in the House and the Democratic party was the majority party under 110th and 111th Congress.

The data set includes the following variables:

1. Roll: The official number that is assigned to each bill proposed. The order of the roll follows the date when the voting occurs.

2. Date: The date when the voting occurs in the floor.

3. Issue: The indication of the types of bills and actions. Bills are included as part of the bill number in the identification code. There are four actions such as QUORUM, JOURNAL, MOTION, and ADJOURN. In terms of bills, there are eight types: (1) H.R. - House Bill, (2) S. - Senate Bill, (3) H.J.Res. - House Joint Resolution, (4) S.J.Res. - Senate Joint Resolution, (5) H.Con.Res. - House Concurrent Resolution, (6) S.Con.Res. - Senate

\footnotetext{
${ }^{29}$ http://www.loc.gov/index.html
} 
Concurrent Resolution, (7) H.Res. - House Simple Resolution, (8) S. Res. Senate Simple Resolution.

4. Question: Summary of bill or action's contents.

5. Result: P means passed, F means failed, and A for agreed to.

6. Sponsor: The representative who sponsors the bill.

7. Sponsor Party: Sponsor's party affiliation

8. Sponsor ADA: Sponsor's ADA score. ADA score means the rankings that ADA (Americans for Democratic Action) assigns to each congressman. ADA members identify key policy issues, and ADA tracks how members of Congress vote on these issues. The annual ADA Voting Record gives each member a rating from 0 , meaning complete disagreement with ADA policies, to 100, meaning complete agreement with ADA policies. A score of 0 is considered conservative and a score 100 is considered liberal.

9. Sponsor DW-NOMINATE Score: DW-NOMINATE score takes the value from the first dimension in the DW-NOMINATE representative ideology scores which are increasing in conservatism (Poole and Rosenthal, 1985b). While the ADA score is based on a selection of 20 bills, the DW-NOMINATE score is constructed based on the every roll call voting records. It is set to take a value between -1 (most liberal) to 1 (most conservative) and it has finer distinctions among representatives in terms of ideology compared to the ADA score. ${ }^{30}$ All the information on DW-NOMINATE score comes from voteview. com.

10. Committee: The principle committee that the bill is referred to.

11. Committee Chair: The principle committee chair's name.

12. Chair Party: The principle committee chair's party affiliation.

13. Chair ADA: The principle committee chair's ADA score.

14. Chair DW-NOMINATE: The principle committee chair's DW-NOMINATE score.

15. Majority Leader: Majority leader in the House.

16. Leader Party: Majority leader's party affiliation.

17. Leader ADA: Majority leader's ADA score.

18. Leader DW-NOMINATE.: Majority leader's DW-NOMINATE score.

\footnotetext{
${ }^{30}$ The bounds on the scores are essentially never reached in our data. For this reason in the subsequent analysis we do not apply limited dependent variable models or a nonlinear transformation of the score-difference.
} 
19. Speaker: The Speaker of the congress.

20. Speaker ADA: Speaker's ADA score.

21. Speaker DW-NOMINATE: Speaker's DW-NOMINATE score.

22. Title Description: A short description on the bill.

23. Special Rule: In the House the majority party leadership schedules legislation for floor debate. Most major legislation is brought to the House floor by a special rule that allows the measure to be taken up out of order. The Rules Committee reports such rules. The rule sets the terms for a measure's floor consideration. Different congresses use different categories of special rules. Therefore, seven coding categories were employed to comprehensively cover the special rules that are used the congress between 107th to 111th. These are:

(a) Open Rules

(b) Modified Open Rules 1 (a time cap on consideration on the amendments)

(c) Modified Open Rules 2 (required amendment pre-printing in the Congressional Record)

(d) Modified Open Rules 3 (both time cap on consideration of amendments and required reprinting in the Congressional Record)

(e) Structured Rules

(f) Structured Rules or Modified Closed Rules

(g) Closed Rules

For the exact definitions of each of these rules for each Congress during the investigated time period, see the Supplementary Appendix.

For some summary facts on the Congresses we consider, see Tables 1-3.

\section{Empirical analysis}

\subsection{Hypotheses}

In this section we test the qualitative predictions of the model presented in Section 4. In the basic specification we use DW-NOMINATE scores to measure biases. In the supplementary appendix, as a robustness check we present the same analysis as below, with ADA scores used.

In the main specification we identify the floor's position with the majority leader's DW-NOMINATE score, and compute the bias of a member as the DWNOMINATE score difference between the member and the majority leader. The majority leader is only second in command after the Speaker. However, since the Speaker does not participate in floor debates and voting and the majority 
leader was more influential under Republican majority during the time period our data cover, we consider it as a more accurate measure of the majority party leadership's political position. In the supplementary appendix we present results based on an alternative specification in which the floor's preference is given by the Speaker's DW-NOMINATE score.

We identify a committee's position with the committee chair's position. We identify the sponsor of a bill as the individual who originally possesses the information necessary for the legislation (the sender in the game introduced in the previous section).

We identify special rules a)-d) (see the end of Section 5) as open rules, and special rules e)-g) as closed rules. We proceeded this way because the definitions of latter rules impose significantly more restrictions on the debate and the possibility of amendments than the rest of the rules, and also because the actual number of amendments is at most a few for bills processed under rules e)-g), while they tend to be large for bills processed under rules a)-d).

From all the rolls that were called on the House floor, we focus on votes "on passage", that is final votes on whether to pass a piece of legislation or not. For the main analysis we only consider legislation that was assigned a special rule and a House committee (on legislation not receiving special rules, see the additional analysis in subsection 6.4). This leaves us with 541 observations for most of the analysis.

The three main qualitative hypotheses that we test are the following.

H1: The likelihood of closed rule is decreasing in the sponsor's bias.

$\mathrm{H} 2$ : The expected committee bias is close to zero when the sponsor's bias is close to zero.

H3: The committee bias is positively associated with the sponsor's bias, in the region of moderate sponsor biases.

To formally address H3, we need to specify the region of sponsor biases that we consider moderate. Because sponsor biases larger than 0.5 in absolute value are clearly outliers in our data, we consider the interval $[-0.5,0.5]$ as an upper bound on the region of moderate biases.

We also test a stronger form of $\mathrm{H} 3$, that for the region of small sponsor biases the expected committee bias goes hand in hand with the sponsor bias.

H3*: For sponsor biases small in absolute value, a unit increase in the sponsor bias is associated with a unit increase in the expected committee bias.

\subsection{Main results}

\subsubsection{Choice of rule as a function of sponsor bias}

To investigate how the sponsor's bias predicts the chosen procedural rule, first we present point estimates from a nonparametric local logistic regression model with the absolute value of the sponsor's bias explaining the probability of closed

rule (see Figure 1). The bandwidth for the regression was fixed to be 0.18 . The graph is qualitatively similar for bandwidths narrower than this value. 
Though both kinds of rules occur under most of the range of sponsor biases in the data, the regression line suggests a discernible decreasing relationship. In the range of data where most of our observations come from, that is for sponsor biases not higher than 0.45 in absolute value, the predicted likelihood of closed rule decreases from more than $90 \%$ to $60 \%$. For even larger sponsor biases the downward trend continues and the predicted probability of closed rule goes to zero, but the estimated regression line in this region should be interpreted with caution, because of the small number of observations. In general the $95 \%$ simultaneous confidence bounds (not shown) are very wide for the whole range of sponsor biases, and for this reason the results from this specification are only suggestive.

Table 4 reports the marginal effect of an increase in the sponsor's absolute bias on the probability of closed rule, from linear and probit regressions. As columns 1 and 3 show, without controls for committee and fixed effects, in both types of regressions we find a significant and large negative relationship. Columns 2 and 4 show that the effect becomes insignificant when introducing committee and congress controls (with the point estimate remaining negative). However, this does not contradict H1, instead suggests that there are not many committees which within the same congress receive both a large number of closed and open procedural rules for their proposals. This can be for example because within a congress a given committee receives referrals that originate from similar sponsors. For this reason we consider the regressions without committee and congress controls to be the correct tests of H1, but also report the regressions with controls for completeness.

Figure 2 takes a closer look at what drives the above result. Among special rules that have a nontrivial number of observations in our data, we see that in the range of sponsor biases where the bulk of the observations are from, the likelihood of the rule remains roughly constant in the sponsor bias for all rules but (a) (pure open) and (g) (pure closed). There is a distinct upward trend in the likelihood of rule (a), and a distinct downward trend in the likelihood of rule (g).

Overall we conclude that even though there is a considerable amount of variation in the data, and both closed and open rules get assigned with positive probability for the whole range of sponsor biases, H1 is largely supported.

\subsubsection{Choice of committee bias as a function of sponsor bias}

For the next set of regressions we restrict our sample to bills that originally get referred to multiple committees, as these are the bills for which the floor has some flexibility in selecting the primary committee responsible for the bill.

First, we investigate which committee gets selected to be the primary one for multiple referral bills. The theoretical prediction is that when the bias of the sponsor is not too large, the selected committee should be the one closest to the sponsor's preferences. Since for all of the bills with multiple referrals in our sample the sponsor bias was in the moderate $[-0.5,0.5]$ range, we conduct this investigation for both all bills with multiple referrals, and for the subsample of 
multiple referral bills for which the sponsor's bias was from the more restrictive $[-0.25,0.25]$ range. As Table 5 shows, for both cases the probability that the committee closest to the sponsor's preferences becomes the primary one is close to $3 / 4$. Moreover, even in cases when the primary committee is not the closest one to the sponsor, the DW-NOMINATE score difference between the finally chosen committee and the closest one is very small: 0.035 and 0.036 for the two samples. This means that for all practical purposes we can assume, in accordance with the theoretical predictions, that the committee closest to the sponsor gets selected as the primary one.

Next, we again consider a local linear regression, with the same fixed bandwidth as before (0.18), to examine the effect of the sponsor bias on the choice of committee bias, for the multiple referrals subsample. Figure 3 displays the point estimates alongside the $95 \%$ confidence bands. Although again there is some variation, there is a clear positive relationship for the whole range of sponsor biases in the subsample. Moreover, the regression line passes close to the origin (the latter is in the $95 \%$ confidence band), indicating that sponsors with biases close to zero on average get associated with committees with bias zero.

The corresponding linear regressions reported in Table 6 confirm that there is a strongly significant positive relationship between committee bias and sponsor bias. As column 2 shows, this result is robust to introducing committee and congress fixed effects. Column 3 shows that the point estimate is even higher when we restrict the sample to sponsor biases $[-0.25,0.25] .{ }^{31}$ However, it stays significantly smaller than 1 even in this region. Therefore results from this specification support $\mathrm{H} 3$, but not $\mathrm{H} 3^{*}$. The intercept is statistically insignificant and very small in magnitude in the specifications without committee and congress fixed effects, and significantly negative when the latter controls are included. For the same reasons spelled out in the previous subsection, we regard the specification with no controls to be the correct one. With this caveat, the results support $\mathrm{H} 2$.

As an alternative approach to investigate the relationship between sponsor bias and committee bias, we also look at how a committee's bias is associated with the average sponsor bias for bills referred to the given committee, during a particular congress (the duration for which the composition of the committee is largely constant). For this investigation we use all bills. Table 7 reports results from this specification. The effect of mean sponsor bias is significantly positive, and larger (closer to 1) than in the previous set of regressions. Column 2 reports a specification in which we restrict attention to committee-congress pairs with more than two observations. This is done in order to partially correct for the fact that this type of regression treats every committee-congress pair as one observation, independently from how many bills are associated with it (nor weighting with the number of bills). This specification reveals an almost exactly unit slope in the linear relationship between committee bias and average sponsor bias for referrals to the committee. Hence the above specifications strongly support H3, and the

\footnotetext{
${ }^{31}$ The results are similar when we restrict the sample to sponsor biases $[-0.2,0.2]$ or $[-0.15,0.15]$.
} 
one corresponding to the second column supports H3*. Moreover, the intercept is small and insignificant in both columns 1 and 2, hence these specifications provide support for $\mathrm{H} 2$.

Overall, we find distinct support in the data for both $\mathrm{H} 2$ and $\mathrm{H} 3$, and more limited support for $\mathrm{H}^{*}$.

\subsection{Alternative specifications: A summary}

The Supplementary Appendix reports results from two alternative specifications, conducted as robustness checks. Here we briefly summarize the findings.

The first specification associates the floor's preferences with the Speaker's DW-NOMINATE score, as opposed to the majority leader's. The relationship between committee bias and sponsor bias is very similar to the main specification. In particular, there is a significant positive linear relationship, robust to including congress and committee fixed effects, with a larger point estimate when restricting the sample to small sponsor biases. The intercept is very small and insignificant for all of these specifications, providing support for H2. Similarly, when regressing committee bias on the average sponsor bias for bills referred to the committee during a given congress, we find a significant positive relationship, and a virtually zero intercept. When we restrict the data set to committee-congress pairs with more than two observations, the estimate of the regression coefficient is 0.95 and not significantly different from 1 . In contrast, the relationship between the probability of closed rule and the absolute value of the sponsor bias becomes insignificant, although negative in all specifications.

The second alternative specification associates the floor's preferences with the ADA score of the majority leader, as opposed to the DW-NOMINATE score. The results are very similar to those from the first alternative specification. There is a significant positive relationship between committee and sponsor bias, more highlighted for small biases. The intercepts are small and insignificant in all specifications. Similar conclusions hold for the specifications regressing committee bias on the average sponsor bias for bills referred to the committee during a given congress. However, the relationship between the probability of closed rule and sponsor bias becomes approximately zero in this specification.

Over all, the results from the main specification with respect to the relationship between committee and sponsor bias are robust to these alternative ways of measuring the floor's preferences, but the results with respect to the relationship between procedural rules and sponsor bias are not. The latter might be attributed to these measures being more noisy indicators of the majority party leadership's preferences than the one used in the main specification.

\subsection{Additional investigation: Legislation receiving no spe- cial rules}

As discussed in Section 3, a fraction of bills do not receive special rules, instead get called up by unanimous consent request or by motions to suspend the rules. In particular, our data contains 52 roll calls that fall into this category. The 
legislative procedure in these cases is similar to strict closed rule, in that debate is severely limited and no amendments are allowed. The difference is that as opposed to closed rule, for which a simple majority is sufficient to pass the legislation, either unanimous support or two-third majority support is required.

Given that these bills are supported by a large fraction of the House representatives, the biases of the sponsor and the committee should be less important for the floor. This suggests that the absolute biases of the sponsors for these bills could be higher than the absolute biases of the sponsors of bills considered under (strict) closed rule. Similarly, we expect the absolute difference between the preferences of the sponsor and the committee for these bills to be larger than for bills considered under closed rule.

We conclude our empirical investigation by formally testing these two predictions. We find evidence in line with both: The absolute sponsor bias of the 152 bills with strict closed rules was 0.157 , while it was 0.22 for votes with no rules. The latter being larger than the former is marginally significant at the $5 \%$ level ( $\mathrm{t}=-1.69)$. Second, the absolute sponsor-committee difference is 0.093 for explicit closed rules and 0.165 for votes without rules, the latter again statistically significantly larger at the $5 \%$ level $(\mathrm{t}=-1.81)$.

\section{Conclusion}

Using roll call data from the House of Representatives, we found support for the main qualitative predictions of an information theory model of legislative decision-making, in which information is strategically passed from the sponsor of a legislation to a committee, and then from the committee to the floor. In particular, the expected bias of the committee is strongly positively associated with the bias of the sponsor, and the likelihood of closed rule is decreasing in the sponsor's absolute bias. At the same time, a considerable amount of variation in the data suggests that other forces are also at play in committee appointments and procedural rule selection.

There are future directions of research that require collecting more data. One is directly investigating the interaction between sponsors and interest groups. It would also be interesting to conduct a closer examination of what type of legislation informational considerations play a more prominent role. Finally, analyzing committee selection in the early days of Congress, before the prevalence of standing committees, would facilitate a more direct test of the theoretically predicted relationship between the sponsor bias and committee bias than the tests conducted in the current paper, based on recent data.

\section{References}

Aghion, P. and J. Tirole (1997): "Formal and Real Authority in Organizations," Journal of Political Economy, 105, 1-29. 
Alonso, R., W. Dessein and N. Matouschek (2008): "When does coordination require centralization?," American Economic Review, 98, 145-179.

Ambrus, A., E. Azevedo and Y. Kamada (2011a): "Hierarchical cheap talk," forthcoming in Theoretical Economics.

Ambrus, A., E. Azevedo, Y. Kamada and Y. Takagi (2011b): "Legislative committees as information intermediaries: A unified theory of committee selection and amendment rules," mimeo, Harvard University.

Ambrus, A. and M. Ivanov (2012): "On the value of mediation," mimeo Duke University.

Ansolabehere, S., J. de Figueiredo and J. Snyder (2003): "Why is there so little money in U.S. politics?," Journal of Economic Perspectives, 17, 105-130.

Austen-Smith, D. (1993): "Information and influence: Lobbying for agendas and votes," American Journal of Political Science, 37, 799-833.

Austen-Smith, D. (1995): "Campaign contributions and access," American Political Science Review, 89, 566-581.

Austen-Smith, D. and J. Wright (1992): "Competitive lobbying for a legislator's vote," Social Choice and Welfare, 9, 229-257.

Austen-Smith, D. and J. Wright (1994): "Counteractive lobbying," American Journal of Political Science, 38, 25-44.

Bach, S. and S. Smith (1988): Managing Uncertainty in the House of Representatives: Adaptation and Innovation in Special Rules, Washington D.C.: Brookings Institution.

Ball, R. (1995): "Interest groups, influence and welfare," Economics and Politics, 7, 119-146.

Bennedsen, M. and S. Feldmann (2002): "Lobbying legislatures," Journal of Political Economy, 110, 919-945.

Bertrand, M., M. Bombardini and F. Trebbi (2011): "Is it whom you know or what you know? An empirical assessment of the lobbying process," mimeo, Chicago University.

Blanes i Vidal, J., M. Draca and C. Fons-Rosen (2010): "Revolving door lobbyists," American Economic Review, forthcoming.

Cai, H. and J. Wang (2006): "Overcommunication in strategic information trans-mission games," Games and Economic Behavior, 56, 7-36.

Cooper, J. and D. Brady (2009): "Institutional Context and Leadership Style," in The American Congress Reader, ed. S. Smith, J. Roberts, and R. Vander Wielen, New York: Cambridge University Press.

Cox, G. and M. McCubbins (1993): Legislative Leviathan: Party Government in the House, New York: Cambridge University Press.

Cox, G. and M. McCubbins (2005): Setting the Agenda: Responsible Party Government in the U.S. House of Representatives, New York: Cambridge University Press.

Crawford, V. and J. Sobel (1982): "Strategic information transmission," Econometrica, 50, 1431-1452.

Deering, C. and S. Smith (1997): Committees in Congress (3rd Edition), Washington D.C.: CQ Press. 
Dessein, W. (2002): "Authority and communication in organizations," Review of Economic Studies, 69, 811-838.

Gilligan, T. W. and K. Krehbiel (1987): "Collective decision-making and standing committees: An informational rationale for restrictive amendment procedures," Journal of Law, Economics and Organization, 3, 287-335.

Gilligan, T. W. and K. Krehbiel (1989): "Asymmetric information and legislative rules with a heterogeneous committee," American Journal of Political Science, 33, 459-490.

Gneezy, U. (2005): "Deception: the role of consequences," American Economic Review, 95, 384-394.

Groseclose, T. and D. C. King (2001): "Committee theories reconsidered," IN L. C. Dodd and B. I. Oppenheimer (ed.s): Congress reconsidered, Washington DC: CQ Press, 191-216.

Hall, R. and A. Deardorff (2006): "Lobbying as Legislative Subsidy" American Political Science Review, 100, 69-84.

Hojnacki, M. and D. Kimball (1998): "Organized interests and the decision of whom to lobby in Congress," American Political Science Review, 92, 775-790.

Holmstrom, B. (1977): "On incentives and control in organizations" (PhD dissertation, Stanford University).

Hurkens, S. and N. Kartik (2009): "Would I lie to you? On social preferences and lying aversion," Experimental Economics, 12, 180-192.

Ivanov, M. (2010): "Communication via a strategic mediator," Journal of Economic Theory, 145, 869-884.

Koempel, M. and J. Schneider (2010): House committee markups: Manuals of procedures and procedural strategies, Congressional Research Service, 29010.

Kollman, K. (1997): "Inviting friends to lobby: Interest groups, ideological bias, and congressional committees," American Journal of Political Science, 41, 519-544.

Krehbiel, K. (2001): "Plausability of signals by a heterogeneous committee," American Political Science Review, 95, 453-456.

Krishna, V. and J. Morgan (2001): "Asymmetric information and legislative rules," American Political Science Review, 95, 435-452.

Langbein, L. (1986): "Money and access: Some empirical evidence," The Journal of Politics, 48, 1052-1062.

Li, T. (2007): "The messenger game: Strategic information transmission through legislative committees," Journal of Theoretical Politics, 19, 489-501.

Lohmann, S. (1995): "Information, access, and contributions: A signaling model of lobbying," Public Choice, 85, 267-284.

Malenko, A. (2011): "Optimal design of internal capital markets," mimeo Stanford University.

Oleszek, W (2010): Congressional Procedures and the Policy Process (8th Edition), Washington D.C.: CQ Press.

Oppenheimer, B. (1977): "The Rules Committee: New Arm of Leadership in a Decentralized House" in Congress Reconsidered, ed. L. Dodd and B. Oppenheimer, New York: Praeger. 
Poole, K. and H. Rosenthal (1985b): "A Spatial Model of Legislative Roll Call Analysis" American Journal of Political Science, 29, 357-384.

Poole, K. and H. Rosenthal (1991): "Patterns of Congressional Voting " American Journal of Political Science, 35, 228-278.

Poole, K. and H. Rosenthal (1997): "Congress: A political-economic history of roll-call voting," Oxford University Press, Oxford.

Sachs, R. (1999): "Sponsorship and Cosponsorship of House Bills " CRS Report for Congress,99-222.

Salisbury, R., P. Johnson, J. Heinz, E. Laumann and R. Nelson (1989): "Who you know versus what you know: The uses of government experience for Washington lobbyists," American Journal of Political Science, 33, 175-195.

Sinclair, B. (2007): Unorthodox Lawmaking: New Legislative Processes in the U.S. Congress (3rd Edition), Washington D.C.: CQ Press.

Smith, S., J. Roberts, and R. Vander Wielen. The American Congress (7th Edition), New York: Cambridge University Press, 2011.

Sullivan, J. (2007): "How Our Laws are Made" Office of the Parliamentarian of the U.S. House of Representatives (24th Edition).

Wang, J., M. Spezio and C. Camerer (2010): "Pinocchio's pupil: Using eyetracking and pupil dilation to understand truth telling and deception in sender-receiver games," American Economic Review, 100, 984-1007.

Wright, J. (1990): "Contributions, lobbying, and committee voting in the U.S. House of Representatives," American Political Science Review, 84, 417-438. 


\begin{tabular}{lllll}
\hline Congress & Majority in House & Minority in House & Majority in Senate & Minority in Senate \\
\hline 107th & Republican (222) & Democrat (210) & Democrat (50) & Republican (50) \\
108th & Republican (222) & Democrat (209) & Republican (51) & Democrat (49) \\
109th & Republican (225) & Democrat (207) & Republican (55) & Democrat (45) \\
110th & Democrat (229) & Republican (203) & Democrat (49) & Republican (49) \\
111 th & Democrat (235) & Republican (198) & Democrat (59) & Republican (41) \\
\hline
\end{tabular}

Table 1: The Composition of Each Congress. Numbers in parenthesis mean the absolute number of members in each party. 


\begin{tabular}{lll}
\hline Congress & Speaker & House Majority Leader \\
\hline 107th & Hastert $(0.448)$ & Armey $(0.636)$ \\
108 th & Hastert $(0.448)$ & Delay $(0.590)$ \\
109 th & Hastert $(0.448)$ & Delay $(0.590)$ \\
110 th & Pelosi $(-0.551)$ & Hoyer $(-0.395)$ \\
111 th & Pelosi $(-0.551)$ & Hoyer $(-0.395)$ \\
\hline
\end{tabular}

Table 2: DW-NOMINATE scores of key actors. Note that these scores are retroactive, and for a given representative we assign his or her latest score for all congresses he or she was present. 


\begin{tabular}{llllll}
\hline Committees & 107th & 108th & 109th & 110th & 111th \\
\hline Agriculture & 0.462 & 0.473 & 0.473 & -0.166 & -0.166 \\
Appropriations & 0.319 & 0.324 & 0.352 & -0.479 & -0.479 \\
Armed Services & 0.694 & 0.481 & 0.481 & -0.178 & -0.178 \\
Budget & 0.424 & 0.424 & 0.424 & -0.326 & -0.326 \\
Education and Workforce & 0.518 & 0.518 & 0.428 & -0.602 & -0.602 \\
Energy and Commerce & 0.355 & 0.540 & 0.540 & -0.469 & -0.514 \\
Financial Services & 0.385 & 0.385 & 0.385 & -0.555 & -0.555 \\
Foreign Affairs & 0.313 & 0.313 & 0.385 & -0.403 & -0.453 \\
House Administration & 0.271 & 0.271 & 0.271 & -0.502 & -0.502 \\
Judiciary & 0.646 & 0.646 & 0.646 & -0.717 & -0.717 \\
Natural Resources & 0.495 & 0.463 & 0.463 & -0.345 & -0.345 \\
Oversight and Government Reform & 0.585 & 0.277 & 0.277 & -0.514 & -0.560 \\
Rules & 0.488 & 0.488 & 0.488 & -0.499 & -0.499 \\
Science and Technology & 0.087 & 0.087 & 0.087 & -0.227 & -0.227 \\
Small Business & 0.506 & 0.506 & 0.506 & -0.599 & -0.599 \\
Transportation and Infrastructure & 0.274 & 0.274 & 0.274 & -0.569 & -0.569 \\
Veterans' Affairs & 0.121 & 0.121 & 0.447 & -0.681 & -0.681 \\
Ways and Means & 0.379 & 0.379 & 0.379 & -0.555 & -0.555 \\
\hline
\end{tabular}

Table 3: DW-NOMINATE score of Committee Chairs 


\begin{tabular}{lcccc}
\hline & $(1)$ & $(2)$ & $(3)$ & $(4)$ \\
\hline Absolute value of sponsor bias & $-0.539^{* *}$ & -0.139 & $-1.729^{* * *}$ & -0.135 \\
& $(0.190)$ & $(0.122)$ & $(0.467)$ & $(0.759)$ \\
\hline Congress FE & & $\mathrm{X}$ & & $\mathrm{X}$ \\
Committee FE & & $\mathrm{X}$ & & $\mathrm{X}$ \\
\hline Observations & 531 & 531 & 531 & 380 \\
$R^{2}$ & 0.037 & 0.395 & & \\
\hline
\end{tabular}

Table 4: Regression analysis

Marginal effects from linear and probit regressions of closed rule use on sponsor bias relative to the majority leader (DW-NOMINATE score). Huber-White standard errors, clustered at the congress-committee level are reported in parentheses. Column (2) controls for committees and congress fixed effects. Columns (3) and (4) show probit models, with or without controls. 
Table 5: The frequency of final committee being the closest one to the sponsor

\begin{tabular}{lcccc}
\hline Final committee is & Full sample & \multicolumn{2}{c}{ Sponsor bias $<0.25$} \\
\hline not the closest & 47 & & 37 & \\
the closest & 128 & & 90 & \\
Total & 175 & & 127 & \\
\hline & & & & \\
\cline { 2 - 5 } & & $(1)$ & $(2)$ & $(3)$ \\
\cline { 2 - 5 } & Sponsor bias & $0.602^{* * *}$ & $0.315^{* *}$ & $0.660^{* * *}$ \\
& $(0.0858)$ & $(0.0971)$ & $(0.0804)$ \\
& Constant & -0.0332 & $-0.244^{*}$ & -0.0298 \\
& $(0.0183)$ & $(0.0977)$ & $(0.0181)$ \\
\cline { 2 - 5 } & Congress FE & & $\mathrm{X}$ & \\
Committee FE & & $\mathrm{X}$ & \\
\cline { 2 - 5 } & Observations & 163 & 163 & 122 \\
$R^{2}$ & 0.384 & 0.683 & 0.307 \\
\hline
\end{tabular}

Table 6: Regression analysis

Linear regressions of the committee bias measured as the absolute distance of committee median from the majority leader, for bills with multiple referrals. Huber-White standard errors, clustered at the congress-committee level are reported in parentheses. Column (2) controls for committees and congress fixed effects. Column (3) repeats column (1) for rolls with small sponsor bias $(<0.25)$. 


\begin{tabular}{lcc}
\hline & $(1)$ & $(2)$ \\
\hline Average sponsor bias & $0.691^{* * *}$ & $0.980^{* * *}$ \\
& $(0.157)$ & $(0.0640)$ \\
Constant & -0.0414 & 0.00250 \\
& $(0.0226)$ & $(0.0161)$ \\
\hline Congress FE & & $\mathrm{X}$ \\
Committee FE & & $\mathrm{X}$ \\
\hline Observations & 85 & 51 \\
$R^{2}$ & 0.437 & 0.752 \\
\hline
\end{tabular}

Table 7: Committee level analysis

OLS regressions of average committee bias on average sponsor bias relative to the majority leader (DW-NOMINATE score), with and without controls. HuberWhite standard errors, clustered at the congress-committee level are reported in parentheses. 
Figure 1: Local logistic regression with fixed bandwidth

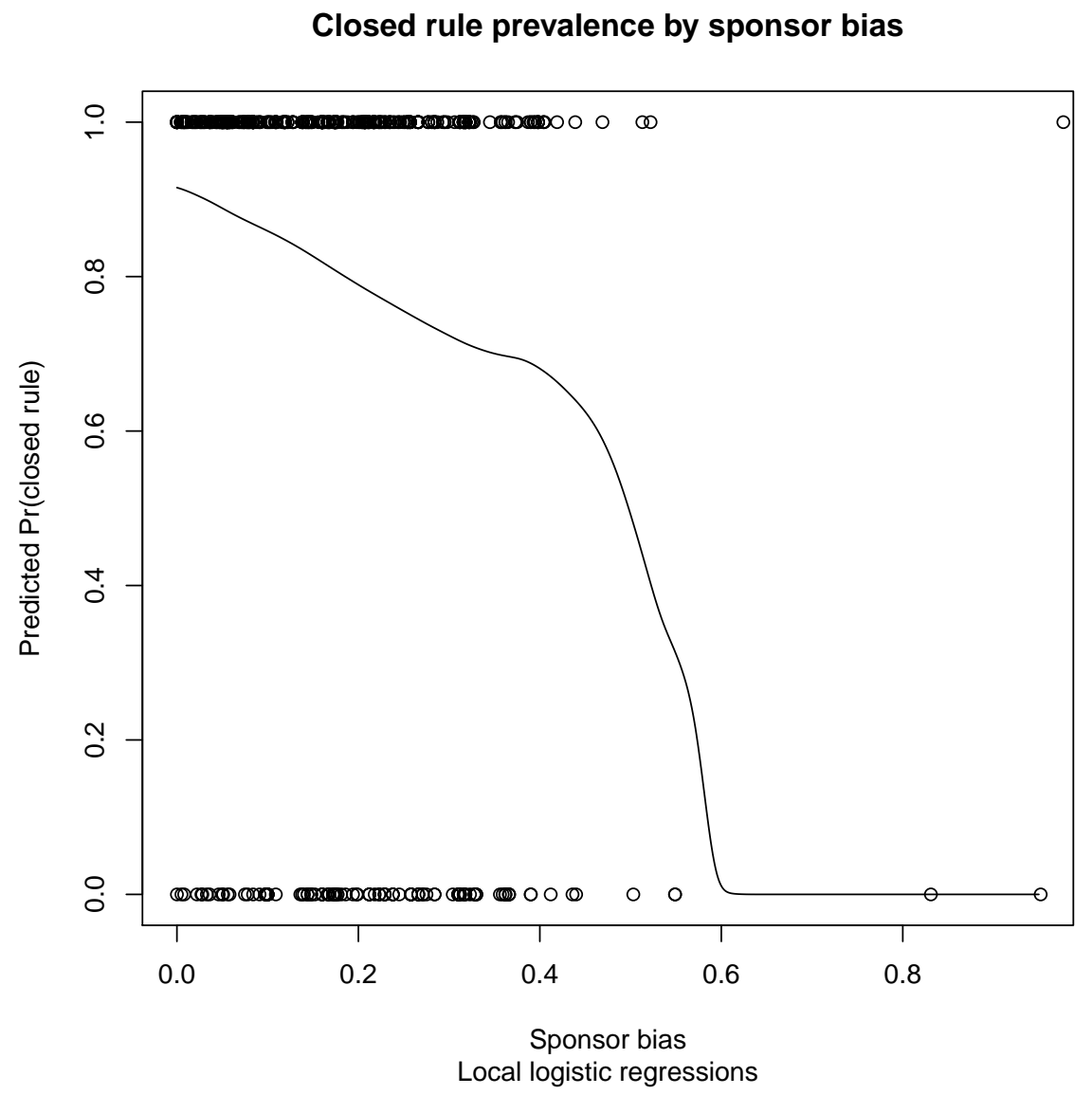

Point estimates for probability of closed rule using a flexible local logistic regression model with the absolute value of the sponsor's bias relative to the majority leader (DW-NOMINATE score), using a bandwidth of 0.18. 
Figure 2: Local logistic regression with fixed bandwidth
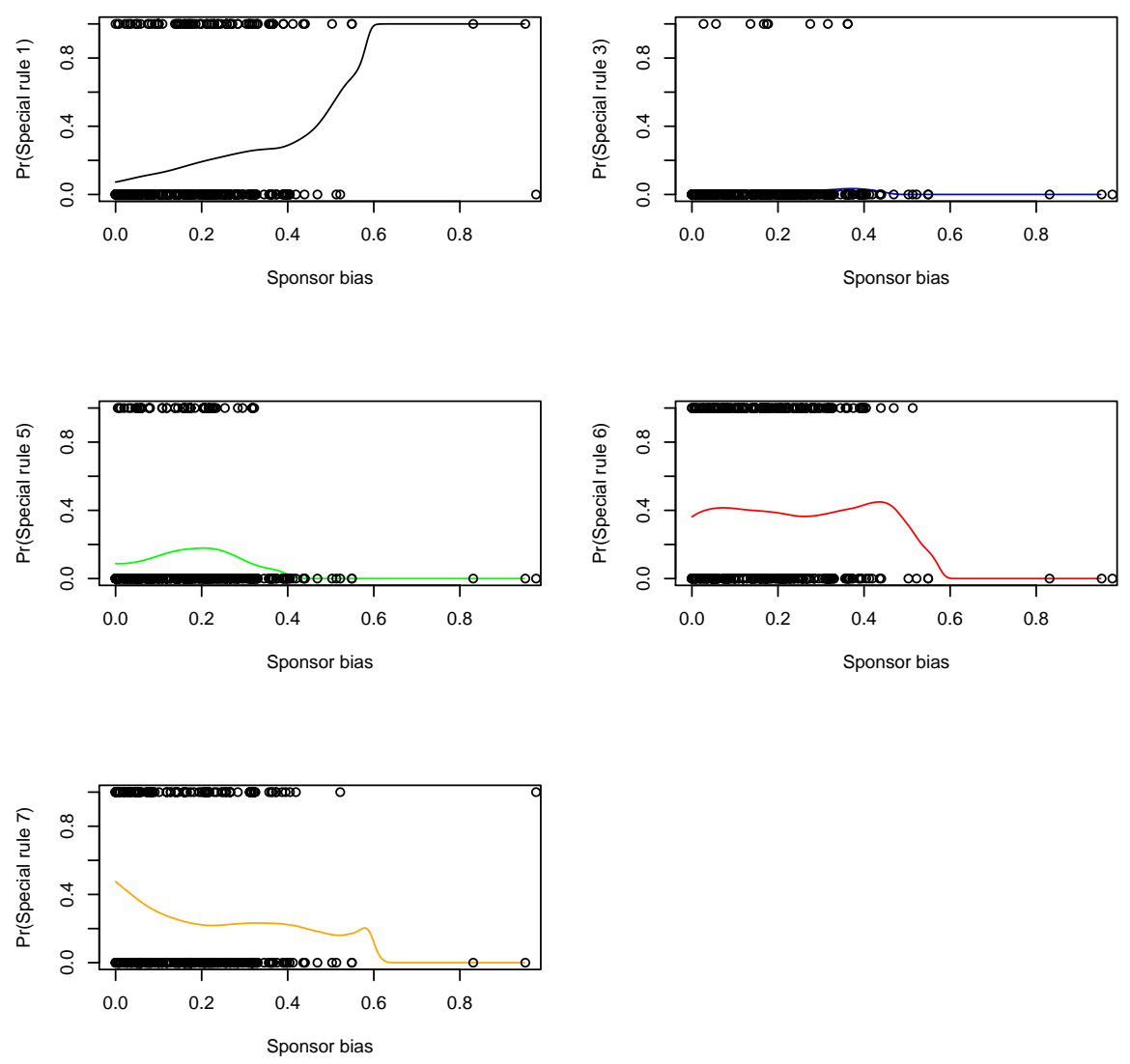

Point estimates for probabilities of different special rules using a flexible local logistic regression model with the absolute value of the sponsor's bias relative to the majority leader (DW-NOMINATE score), using a bandwidth of 0.18. 
Figure 3: Local linear regression, biases relative to the majority leader (DWNOMINATE score), for bills with multiple referrals only

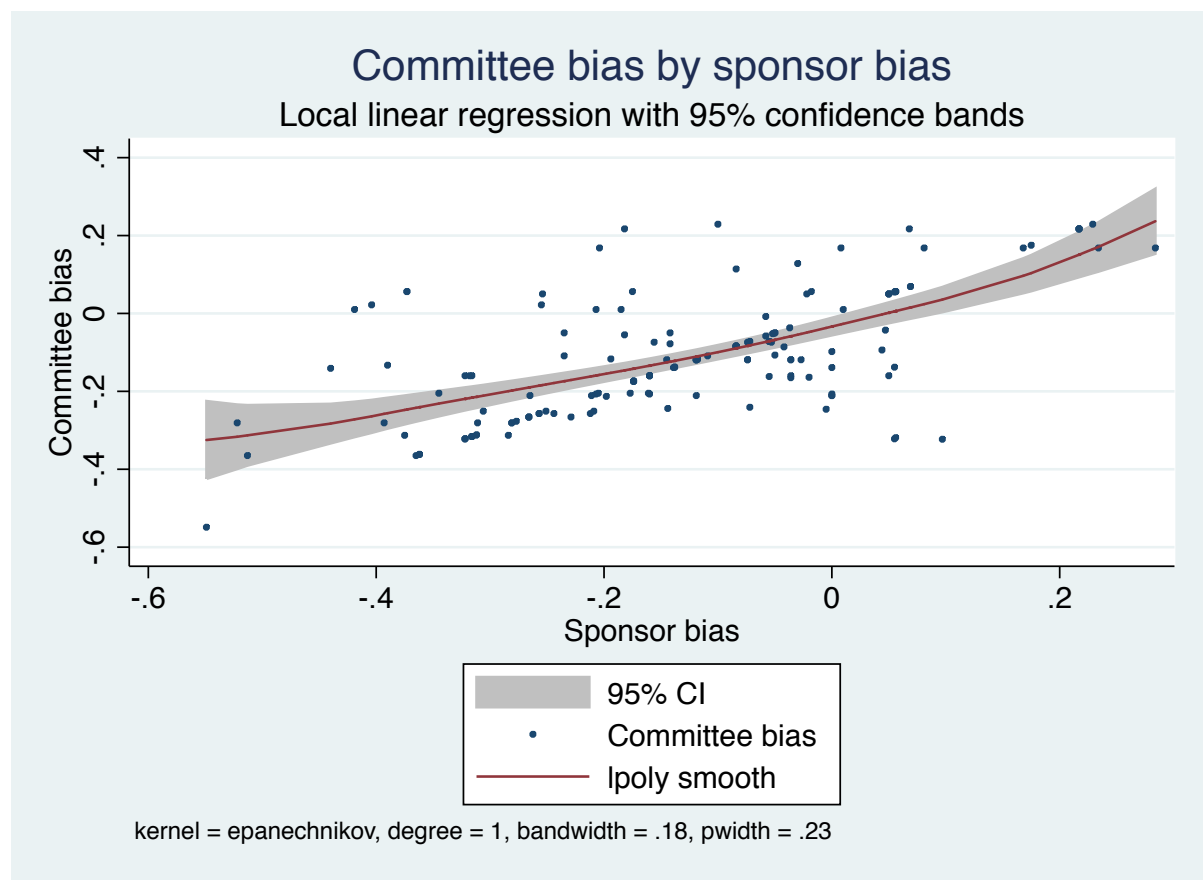

